\title{
Resistance Training Effect on Lipid Profile and Body Fat Percentage of Premenopausal Women
}

\author{
Parvin Heydarpour ${ }^{1}$; Sadigheh Fayazi ${ }^{2, *}$; Shayesteh Haghighi ${ }^{2}$ \\ ${ }^{1}$ Diabetes Research Center, Nursing and Midwifery School, Ahvaz Jundishapur University of Medical Sciences, Ahvaz, IR Iran \\ ${ }^{2}$ Chronic Disease Care Research Center, Department of Nursing, Nursing and Midwifery School, Ahvaz Jundishapur University of Medical Sciences, Ahvaz, IR Iran \\ ${ }^{*}$ Corresponding author: Sadigheh Fayazi, Chronic Disease Care Research Center, Department of Nursing, Nursing and Midwifery School, Ahvaz Jundishapur University of Medical \\ Sciences, Ahvaz, IR Iran. Tel: +98-9161136441, E-mail:Sadighe_fa@yahoo.com
}

Received: March 1, 2015; Accepted: March 27, 2015

Background: Obesity and lipid profile are major risk factors for noncommunicable diseases, especially cardiovascular diseases and diabetes. In this regard, improving indicators of abdominal obesity and lipid profiles is necessary.

Objectives: The purpose of this study was to investigate the effects of endurance exercise on abdominal obesity and lipid profile in premenopausal women living in Mahshahr City, Iran.

Patients and Methods: This study was a randomly and controlled clinical trial. For this purpose, 40 obese women (age range, 38-52 years) with Body Mass Index (BMI) of 28.8 to $30.6 \mathrm{~kg} / \mathrm{m}^{2}$ were assigned to either a non-exercising control group or a resistance exercise training group. The resistance exercise training group took part in supervised 45-to 50-minute resistance training sessions, 3 times per week on nonconsecutive days for 10 weeks. The control group did not take part in any structured physical activity.

Results: Two-way analysis of variance with $t$ test and student $t$ test measures showed significant $(P<0.05)$ increase in the strength level in the exercise group. There were significant $(\mathrm{P}<0.05)$ decreases in total cholesterol and body fat percentage $(\mathrm{P}<0.05)$, but we found no significant difference in triglycerides (high density lipoprotein and low density lipoprotein) between two groups.

Conclusions: These findings suggest that resistance training has a favorable effect on total cholesterol and body fat percentage in premenopausal women, but has no significant effect on others the lipid profiles. The participants were followed just for 10 weeks, further studies with longer duration are recommended.

Keywords: Exercise; Physical Endurance; Abdominal Obesity; Lipids

\section{Background}

The prevalence of cardiac risk factors among women has increased in the past decade. Obesity and diabetes rates are increasing and show a marked variation by race or ethnicity. According to 2006 statistics from the Centers for Disease Control (CDC), 31.3\% of white women and $53.2 \%$ of black women are obese (1). Noncommunicable diseases frequently cause death over prolonged periods after initial diagnosis, and require extensive and expensive treatments. Physical inactivity has direct effect on the development of noncommunicable chronic diseases (2). Prospective epidemiological studies have shown that obesity and abdominal obesity are closely related to dyslipidemia and obese or overweight person mostly show lipid disorders. Increased blood levels of cholesterol and triglycerides are recognized as risk factors for cardiovascular diseases. However, the level of HDL (high density lipoprotein) can be considered as a protective measure against the disease (3).

Obesity in general and abdominal obesity in particular are associated with lipids disorder due to risk factors of noncommunicable diseases, which is another major risk factor in women (4). In 2008, more than 1.4 billion adults, 20 years and older, were overweight, of these nearly 300 million women were obese (5). Many studies show that the metabolic complications of obesity are rising not only in developed countries but also in developing countries (6). In fact, obesity can be presented as (new world syndrome) the greatest health problem in the modern industrial world (7). American women (mainly premenopausal women) typically gain $0.5-1 \mathrm{~kg}$ yearly $(8,9)$. Such weight gain, mainly in terms of fat gain (10-12), leads to an increased prevalence of unhealthy weight and obesity in old age (12). Excess adiposity, particularly excess abdominal fat, has been shown to increase the risk of morbidity caused by a number of health conditions, including cardiovascular diseases and type 2 diabetes (13). Abdominal obesity was present in $43.4 \%$ of women, $9.7 \%$ of men, $28.5 \%$ of the urban residents, and $23 \%$ of the rural residents. A study in Iran has shown that abdominal obesity was present in $43.4 \%$ of women and $9.7 \%$ of men. Also, $48 \%$ of adults are overweight or obese and $43.3 \%$ have abdominal obesity. Abdominal obesity is more common in 45-years adults and older (14). The prevalence of abdominal obesity in Iranian men and women are 63\% and $84 \%$, respectively (15).

Although the etiology of the rising prevalence of obesity is still poorly understood, lower physical activity level has been blamed for the weight gain (16). But, hormonal

Copyright (C) 2015, Ahvaz Jundishapur University of Medical Sciences. This is an open-access article distributed under the terms of the Creative Commons Attribution-NonCommercial 4.0 International License (http://creativecommons.org/licenses/by-nc/4.0/) which permits copy and redistribute the material just in noncommercial usages, provided the original work is properly cited. 
changes associated with menopause, chronological aging, and lifestyle, especially physical activity, may all influence the changes in body composition and fat distribution experienced by midlife women $(17,18)$. Women close to menopausal age have a tendency to gain weight and abdominal obesity is a serious health threat to women at this age. The reason to this weight gain is not well known, but researchers have introduced reduced physical activity as one of the main causes (19). Despite evidence indicating that proper levels of physical activity are associated with $30 \%$ reduction in the risk of ischemic heart disease, $27 \%$ reduction in the risk of diabetes, and 21 - $25 \%$ reduction in the risk of breast and colon cancer, approximately 3.2 million deaths are attributed to the insufficient physical activity each year (20). Epidemiological evidence suggests that physically active individuals have 30 - 50\% lower risk of developing cardiovascular or type 2 diabetes compared to sedentary persons. Physical exercise without diet restriction has proven to improve lipid blood profiles and to decrease fat mass. The most efficient mode of exercise to improve the response on lipid profile is unknown. There are studies that examine the effects of different exercise modes on blood lipid levels in sedentary adults engaging exercise intervention (21). High intensity resistance training has been reported to improve body composition and strength (18-20), with no significant change in aerobic capacity (22-25). The effect of acute and chronic (25-26) resistance training on lipid metabolism has been studied less than aerobic training, but there are reports of improved lipid profiles in both men and women after high intensity resistance training $(25,26)$. However, there is a dearth of well-controlled studies on the effect of resistance training on lipid metabolism in premenopausal women. Reductions in total and LDL cholesterol have been reported in premenopausal women after resistance training at $70 \%$ of one-repetition-maximum (27). The results of some studies are difficult to interpret owing to poor design, inadequate control of factors known to influence lipid metabolism, and lack of statistical power. Intervention studies have not consistently demonstrated improvement in women's lipid and lipoprotein profiles with change in activity (28). Therefore, the purpose of this investigation was to study the effects of a supervised, intensive 10 week resistance training regimen on lipid profile and body fat percentage in healthy, sedentary, premenopausal women. The results of some studies have shown different findings about the effect of the exercise on lipids profile and obesity. Unfortunately, abdominal obesity and dyslipidemia are increasing in Iranian women.

\section{Objectives}

The purpose of this investigation was to study the effects of aerobic exercise on abdominal obesity and dyslipidemia in premenopausal women.

\section{Patients and Methods}

This study was a randomized and controlled clinical trial in order to investigate the effect of aerobic exercise train- ing on abdominal obesity and lipid profile in pre-menopausal women. The study population consisted of women with abdominal obesity and lipid disorders referred to Health Family department in Mahshahr (Shahid Beheshti clinic of Petrochemical Hospital). Inclusion criteria were age range between 38 - 52 years old, literate, unpregnant (confirmed by last menstrual period), waist circumference more than $88 \mathrm{~cm}$ or waist-to-hip ratio greater than 0.85 and having at least one abnormal lipid profile pattern (TG > $200 \mathrm{mg} / \mathrm{dL}, \mathrm{TC}>200 \mathrm{mg} / \mathrm{dL}, \mathrm{HDL}<50 \mathrm{mg} / \mathrm{dL}, \mathrm{LDL}>130 \mathrm{mg} /$ $\mathrm{dL})$; not under any anti-fat, weight loss , and corticosteroid drugs; no known heart and respiratory disease, no history of epilepsy, neurological, muscular disease and diabetes; no major surgery in the last 6 months and lack of regular physical activity during previous 6 months. The exclusion criteria in interventional group were the following: irregular participation in training sessions; absence in exercises, (consecutive or intermittent) for more than 3 sessions; participation in other training sessions; using steroidal, antifat, or any kind of weight loss drugs. The exclusion criteria in the control group were the following: participation in exercise sessions more than twice a week; using steroid, anti-fat, or any kind of weight loss drugs. To access the study samples a recommendation was taken from Jundishapur University for referring to Shahid Beheshti Clinic and obtaining approval from the relevant authorities. Volunteers were selected by interview and based on the inclusion and exclusion criteria. The subjects were randomly divided into two groups and the control group underwent endurance exercise. The sample comprised 40 persons that during the study 9 of them were dropped due to exclusion criteria. The Ethics Committee of Ahvaz Jundishapur University of Medical Sciences approved the study (ETH-211). Formal authorization was obtained from College of Nursing and Midwifery of Ahvaz Jundishapur University of Medical Sciences and the Mahshahr Oil Hospital for both the sampling and the study. Both the purpose and method of the research were explained for the participants, and informed consent to participate in the study was received from all of them. Demographic information, medical history, and reproductive history were collected at base line. They included participants' weight and height measured in light clothing without shoes by a nurse and scholar. Indexes of abdominal obesity in this study were waist circumference, hip circumference and waist-to-hip ratio, which were also measured. The day before the exercise, lipid profile was measured and conducted by the laboratory at 8 AM after 12 hours of fasting. Waist circumference and hip circumference were measured in the narrowest part of the waist in the body, without imposing any pressure to body in case the individual was at the end of exhalation. Hip circumference was measured using a tape measure at the most prominent part without imposing any pressure to body surface. Measurements were done before breakfast in the morning at the clinic. In this study, endurance aerobic exercise of moderate intensity was done 3 days a week for 10 weeks. The total number of training sessions was 30 ses- 
Heydarpour P et al.

sions. Training was designed by a researcher and sport consulting. Exercise training had been performed at 9-10 AM in the morning. Measurements of lipid profiles (triglyceride, cholesterol, HDL, and LDL) were done by auto-analyzer (BT 3000 and Pars test kits). Data were analyzed by SPSS 17. Independent $t$ test were used to compare means of obesity and lipid profiles in both interventional and control group.

\section{Results}

The mean age (SD) of participants in this study was 44.6 $( \pm 4.05)$ years; $58 \%$ of subjects had moderate level of education; and all of them were married and housewives. Table 1 presents the mean \pm SD of pre- and post-training values for the waist, abdominal, hip circumference, as well as waist to hip ratio before and after the intervention between case and control groups. There were statistically significant differences between two groups regarding the abdominal and waist circumference before and after 8 weeks of aerobic exercise training $(\mathrm{P}<0.05)$. Table 1 presents the summary data for hip circumference, and waist to hip ratio. There were no significant differences between two groups before and after training program $(P>0.05)$. In other words, the aerobic exercise training intervention had no significant effect on hip circumference and waist to hip ratio (WHR). Table 2 shows the effect of the aerobic exercise training intervention on cholesterol, triglyceride (TG), high density lipoprotein (HDL), and low density lipoprotein (LDL). We did not observe a significant change in these parameters before and after the intervention between groups, except cholesterol $(\mathrm{P}=$ 0.02 , Table 2 ). Table 3 presents the mean \pm SD of pre- and post-training values for the body weight and BMI. The aerobic exercise training intervention had significant effect (reduction) on body weight and BMI $(\mathrm{P}<0.05)$ (Table 3).

Table 1. Comparison of Mean Indexes of Waist, Abdominal Circumference, Hip Circumference and Waist to Hip ratio Before And After the Intervention Between Case and Control Groups a

\begin{tabular}{|c|c|c|c|c|c|}
\hline Group & $\begin{array}{l}\text { Average Value Be- } \\
\text { fore Intervention }\end{array}$ & $\begin{array}{l}\text { Average Value Af- } \\
\text { ter Intervention }\end{array}$ & $\begin{array}{l}\text { Mean Difference } \\
\text { Before and After } \\
\text { Intervention }\end{array}$ & $\begin{array}{l}\text { Standard Deviation } \\
\text { Difference Before and } \\
\text { After Intervention }\end{array}$ & PValue \\
\hline Waist circumference & & & & & $P=0.03$ \\
\hline Case $(n=16)$ & $88.3 \pm 9.9$ & $86.5 \pm 9.8$ & 1.8 & 3.6 & \\
\hline Control $(n=15)$ & $88.8 \pm 8.7$ & $89.4 \pm 4.6$ & 0.06 & 2.3 & \\
\hline $\begin{array}{l}\text { Abdominal } \\
\text { circumference }\end{array}$ & & & & & $P=0.01$ \\
\hline Case $(n=16)$ & $98.5 \pm 13.2$ & $96.25 \pm 11.7$ & 2.25 & 2.97 & \\
\hline Control $(n=15)$ & $96.7 \pm 6.1$ & $98.6 \pm 7.8$ & -1.8 & 5.05 & \\
\hline Hip circumference & & & & & $P=0.05$ \\
\hline Case $(n=16)$ & $111.06 \pm 9.1$ & $109.09 \pm 8.8$ & 1.97 & 1.6 & \\
\hline Control $(n=15)$ & $109.3 \pm 7.6$ & $109.3 \pm 7.3$ & 0.00 & 2.1 & \\
\hline Waist to hip ratio & & & & & $P=0.3$ \\
\hline Case $(n=16)$ & $0.78 \pm 0.05$ & $0.78 \pm 0.04$ & 0.003 & 0.03 & \\
\hline Control $(n=15)$ & $0.8 \pm 0.03$ & $0.81 \pm 0.03$ & -0.006 & -0.00 & \\
\hline
\end{tabular}

\begin{tabular}{|c|c|c|c|c|c|}
\hline Group & $\begin{array}{l}\text { Average Value Be- } \\
\text { fore Intervention }\end{array}$ & $\begin{array}{l}\text { Average Value Af- } \\
\text { ter Intervention }\end{array}$ & $\begin{array}{l}\text { Mean Difference } \\
\text { Before and After } \\
\text { Intervention }\end{array}$ & $\begin{array}{c}\text { Standard Deviation } \\
\text { Difference Before and } \\
\text { After Intervention }\end{array}$ & PValue \\
\hline Cholesterol & & & & & $P=0.02$ \\
\hline Case $(n=16)$ & $207.4 \pm 31.3$ & $203 \pm 37.1$ & 4.4 & 22 & \\
\hline Control $(n=15)$ & $206.1 \pm 31.6$ & $228.8 \pm 29.6$ & -22.7 & 42 & \\
\hline TG & & & & & $P=0.7$ \\
\hline Case $(n=16)$ & $159.8 \pm 10.6$ & $141.4 \pm 69.4$ & 18.4 & 78.4 & \\
\hline Control $(n=15)$ & $149.1 \pm 65.8$ & $136.6 \pm 45.2$ & 12.5 & 46.1 & \\
\hline \multicolumn{6}{|l|}{ HDL } \\
\hline Case $(n=16)$ & $61.6 \pm 14.1$ & $64.3 \pm 20.7$ & 2.7 & 20.7 & $P=0.1$ \\
\hline Control $(\mathrm{n}=15)$ & $57.8 \pm 13.8$ & $70.9 \pm 22.7$ & 13.1 & 22.8 & \\
\hline \multicolumn{6}{|l|}{ LDL } \\
\hline Case $(n=16)$ & $112.6 \pm 29.5$ & $115.1 \pm 30.1$ & -2.5 & 18 & $P=0.4$ \\
\hline Control $(\mathrm{n}=15)$ & $120 \pm 19.3$ & $129 \pm 14.4$ & -9 & 37 & \\
\hline
\end{tabular}

a Abbreviations: TG, triglyceride; HDL, high density lipoprotein; LDL, low density lipoprotein.

b Data are presented as Mean \pm SD. 
Table 3. Comparison of Mean Weight and Body Mass Index of Participants Before and After the Intervention Between Case and Control Groups ${ }^{a}$

\begin{tabular}{|c|c|c|c|c|c|}
\hline Group & $\begin{array}{l}\text { Average Value Be- } \\
\text { fore Intervention }\end{array}$ & $\begin{array}{l}\text { Average Value Af- } \\
\text { ter Intervention }\end{array}$ & $\begin{array}{c}\text { Mean Difference } \\
\text { Before and After } \\
\text { Intervention }\end{array}$ & $\begin{array}{l}\text { Standard Deviation } \\
\text { Difference Before and } \\
\text { After Intervention }\end{array}$ & P Value \\
\hline Weight & & & & & 0.02 \\
\hline Case $(n=16)$ & 73.8 & 72.8 & 1.0 & 1.5 & \\
\hline Control $(\mathrm{n}=15)$ & 72.6 & 73 & -0.4 & 1.6 & \\
\hline BMI & & & & & 0.01 \\
\hline Case $(n=16)$ & 30.6 & 30.07 & 0.5 & 1.5 & \\
\hline Control $(\mathrm{n}=15)$ & 28.8 & 29.06 & -0.2 & 1.6 & \\
\hline
\end{tabular}

\section{Discussion}

The finding of the present study showed that the mean and standard deviation of the waist and abdomen circumferences significantly decreased. These changes in the case group occurred compared with the control group after 10 weeks of exercise $(P<0.05)$. Thus, this significant reduction compared to the control group indexes after endurance exercise could be due to the effect of training exercise program on these parameters. This finding is consistent with a previous study that examined the effects of endurance, resistance, and concurrent exercise programs on abdominal obesity indexes (waist to hip ratio, waist circumference, waist to height ratio) in middle-aged women with abdominal obesity for 8 weeks. The obtained results showed that endurance and resistance training had significant positive changes on waist and abdomen obesity in the case group (29). The results of the present study showed that there was no significant decrease of LDL in the subject group after 10 weeks. However, the findings showed increased LDL in control group. Also in the present work, no significant changes were observed in HDL and TG level. These findings are in conformity with a study done to evaluate the effect of aerobic dance on blood lipoprotein in premenopausal women. The training group exercised aerobic dance twice a week for 3 months. It was alleged that 12 weeks of training did not result in any significant alteration of blood lipoproteins (30). They reported that there were no changes in triglycerides, total cholesterol, LDL, and HDL in the training group after the training period. Our results (except for the decrease in cholesterol) are in agreement with the work of Ball and Golhofner (31). Therefore, no changes in HDL, LDL, and TG in the participants were due to the duration, length, and frequency of the training program. The decrease in the cholesterol level after the endurance training is in conformity with the studies of Narayani and Sudhan (32) who concluded that the aerobic training is widely believed to induce changes in the lipid profiles of women. This study suggested that physical activity appeared to have an indirect association with the serum lipid and lipoprotein values through its relation with higher and lower levels of fatness. Another study done by Vatansev et al. (33) determined the effects of 8 weeks aerobic exercise program on body composition and blood lipids of middle-aged women. They reported that there was significant difference $(\mathrm{P}<0.05)$ between the tests of BW and BMI after 8-week aerobic-step exercise (33). Their results support findings of the present study. Also in our results, we did not observe significant change in WHR index between the two groups after the completion of the study. This finding is consistent with the findings of previous study by You et al. (34) who reported that weight loss alone decreased both waist and hip girths; however, there was no change in waist to hip ratio. The purpose of that investigation was to assess whether hypocaloric diet, diet plus low-intensity exercise, and diet plus high-intensity exercise differentially influence subcutaneous abdominal fat in obese middle-aged women. No significant change in WHR index in our result is inconsistent with the work of Wing et al. (35). As a result, exercises cause favorable changes in lipids profile and obesity, however it requires additional investigation. Furthermore, diet program in addition to exercise will provide more prolific results and this difference is probably related to differences in the subjects of this study as well as the intensity and duration of training sessions. According to the findings of present study and other studies, it can be concluded that absence of above mentioned significant variables after endurance aerobic exercise in the present study is probably due to differences in type, and duration of training, nutrition, and gender of persons.

Limitations of the present study were the short duration of the intervention and incomplete dietary data because we were unable to collect and analyze the diet plan of the participant. The findings of this study revealed that endurance aerobic training in middle-aged women had a positive influence on weight, abdominal, and waist circumference measures. It also showed that endurance training has a positive effect on blood cholesterol but no significant effect on the blood triglyceride, high density 
lipoprotein, low density lipoprotein profiles and waist to hip ratio. According to our results, it might be necessary to increase duration or frequency of the exercise sessions in endurance aerobic training if decreasing total lipid profiles are desired in premenopausal women.

Perspective: There is much evidence that a regular program of physical activity can help manage many of the uncomfortable symptoms of premenopausal related health problems and reduce risk factors such as lipid disorder and weight gain. We were very much interested to examine the effects of aerobic exercise on abdominal fat and lipid profile without observing any diet. We expected aerobic exercise promoting the loss of abdominal fat, the place that most women more readily gain weight during premenopausal age. We also expected that the level of lipid profiles positively changes during 10 weeks training program, although our findings did not show favorable changes in all of lipid profiles. Apparently besides exercise, a good nutrition is vital to realize the full benefits of the exercise.

\section{Acknowledgements}

We thank Mahshahr Oil Hospital staff and all who helped us in this research.

\section{Funding/Support}

This paper was extracted from a thesis submitted by Parvin Heydari and was financially supported (grant No: 201103037456n1) by Vice Chancellor for Disease Research Centre of Ahvaz Jundishapur University of Medical Sciences.

\section{References}

1. Coulter SA. Epidemiology of cardiovascular disease in women: risk, advances, and alarms. Tex Heart Inst J. 2011;38(2):145-7.

2. Blair SN, Sallis RE, Hutber A, Archer E. Exercise therapy - the public health message. Scand J Med Sci Sports. 2012;22(4):e24-8.

3. Jain N, Koley S, Sandhu JS. A Study of Correlation between Intraabdominal Fat and Lipid Profiles and Some Anthropometric Parameters in Vegetarian and Non-vegetarian Middle Aged Women of Jabalpur, Madhya Pradesh. Anthropol. 2009;11(2):77-81.

4. Hosseinpanah F, Barzin M, Eskandary PS, Mirmiran P, Azizi F. Trends of obesity and abdominal obesity in Tehranian adults: a cohort study. BMC Public Health. 2009;9:426.

5. World Health Organization.. Media centre Overweight and Obesity Database.: WHO; 2013. Available from: http://www.who.int/mediacentre/factsheets/fs311/en/.

6. Ren J. Leptin and hyperleptinemia - from friend to foe for cardiovascular function.J Endocrinol. 2004;181(1):1-10.

7. Nammi S, Koka S, Chinnala KM, Boini KM. Obesity: an overview on its current perspectives and treatment options. Nutr J. 2004;3:3.

8. Lewis CE, Jacobs DJ, McCreath H, Kiefe CI, Schreiner PJ, Smith DE, et al. Weight gain continues in the1990s:10-year trends in weight and overweight from the CARDIA study. Coronary Artery Risk Development in Young Adults. Am J Epidemiol. 2000;151(12):1172-81.

9. Williamson DF. Descriptive epidemiology of body weight and weight change in U.S. adults. Ann Intern Med. 1993;119(7 Pt 2):646-9.

10. Going S, Williams D, Lohman T. Aging and body composition: biological changes and methodological issues. Exerc Sport Sci Rev. 1995;23:411-58.
11. Forbes GB. Longitudinal changes in adult fat-free mass: influence of body weight. Am J Clin Nutr. 1999;70(6):1025-31.

12. Flegal KM, Carroll MD, Ogden CL, Johnson CL. Prevalence and trends in obesity among US adults, 1999-2000. JAMA. 2002; 288(14):1723-7.

13. Smith SCJ. Multiple risk factors for cardiovascular disease and diabetes mellitus. Am JMed. 2007;120(3 Suppl 1):S3-S11.

14. Kelishadi R, Alikhani S, Delavari A, Alaedini F, Safaie A, Hojatzadeh E. Obesity and associated lifestyle behaviours in Iran: findings from the First National Non-communicable Disease Risk Factor Surveillance Survey. Public Health Nutr. 2008;11(3):246-51.

15. Hosseinpanah F, Barzin M, Sarbakhash Eskandary P, Mirmiran P, Azizi F. Prevalence of overweight, obesity and abdominal obesity in adults living in District 13 of Tehran during 1378-81.J Shahid Beheshti Univ. 2005;2:123-9.

16. Poehlman ET, Toth MJ, Bunyard LB, Gardner AW, Donaldson KE, Colman E, et al. Physiological predictors of increasing total and central adiposity in aging men and women. Arch Intern Med. 1995;155(22):2443-8.

17. Sternfeld B, Ainsworth BE, Quesenberry CP. Physical activity patterns in a diverse population of women. Prev Med. 1999; 28(3):313-23.

18. Marandi SM, Abadi NG, Esfarjani F, Mojtahedi H, Ghasemi G. Effects of intensity of aerobics on body composition and blood lipid profile in obese/overweight females. Int J Prev Med. 2013;4(Suppl 1):S118-25.

19. Sternfeld B, Wang H, Quesenberry CJ, Abrams B, Everson-Rose SA, Greendale GA, et al. Physical activity and changes in weight and waist circumference in midlife women: findings from the Study of Women's Health Across the Nation. Am J Epidemiol. 2004;160(9):912-22.

20. Lachat C, Otchere S, Roberfroid D, Abdulai A, Seret FM, Milesevic J, et al. Diet and physical activity for the prevention of noncommunicable diseases in low- and middle-income countries: a systematic policy review. PLoS Med. 2013;10(6).

21. Romero Moraleda B, Morencos E, Peinado AB, Bermejo L, Gomez Candela C, Benito PJ, et al. Can the exercise mode determine lipid profile improvements in obese patients? Nutr Hosp. 2013;28(3):607-17.

22. Smutok MA, Reece C, Kokkinos PF, Farmer C, Dawson P, Shulman $\mathrm{R}$, et al. Aerobic versus strength training for risk factor intervention in middle-aged men at high risk for coronary heart disease. Metabolism. 1993;42(2):177-84.

23. Blumenthal JA, Matthews K, Fredrikson M, Rifai N, Schniebolk $\mathrm{S}$, German D, et al. Effects of exercise training on cardiovascular function and plasma lipid, lipoprotein, and apolipoprotein concentrations in premenopausal and postmenopausal women. Arterioscler Thromb. 1991;11(4):912-7.

24. Nakao M, Inoue Y, Murakami H. Longitudinal study of the effect of high intensity weight training on aerobic capacity. Eur J Appl Physiol Occup Physiol. 1995;70(1):20-5.

25. Hurley BF, Hagberg JM, Goldberg AP, Seals DR, Ehsani AA, Brennan RE, et al. Resistive training can reduce coronary risk factors without altering VO2max or percent body fat. Med Sci Sports Exerc. 1988;20(2):150-4.

26. Goldberg L, Elliot DL, Schutz RW, Kloster FE. Changes in lipid and lipoprotein levels after weight training. JAMA. 1984; 252(4):504-6.

27. Boyden TW, Pamenter RW, Going SB, Lohman TG, Hall MC, Houtkooper LB, et al. Resistance exercise training is associated with decreases in serum low-density lipoprotein cholesterol levels in premenopausal women. Arch Intern Med. 1993;153(1):97-100.

28. Kelley GA, Kelley KS. Impact of progressive resistance training on lipids and lipoproteins in adults: a meta-analysis of randomized controlled trials. Prev Med. 2009;48(1):9-19.

29. Nikpour S, Vahidi SH, Hedayati M, Haghani H, AghaAlinejad H, Soudmand B. The Effect of Rhythmic Endurance Training on Abdominal Obesity Indices Among Working Women in Iran University of Medical Sciences. Iran J Metabologia Metab. 2010;11(2):177-83.

30. Schiffer T, Schulte S, Sperlich B. Health and Fitness effect on middle aged premenopausal women.J Exerc . 2008;11(4):25-33. 


\section{Heydarpour P et al.}

31. Ball S, Golhofner A. Comparison of a commercial weight loss program to a fitness center.J Exerc Physiol. 2008;11(3):1-12.

32. Narayani U, Sudhan PR. Effect of aerobic training on percentage of body fat, total cholesterol and HDL-C among obese women. World J Sport Sci. 2010;3(1):33-6.

33. Vatansev H, Cakmakci E. The effect of 8 week aerobic exerciseon the bloob lipid and body composition of the overweight and obese female.J Master List. 2010;2:814-8.
34. You T, Murphy KM, Lyles MF, Demons JL, Lenchik L, Nicklas BJ. Addition of aerobic exercise to dietary weight loss preferentially reduces abdominal adipocyte size. Int J Obes (Lond). 2006;30(8):1211-6.

35. Wing RR, Jeffery RW, Burton LR, Thorson C, Kuller LH, Folsom AR. Change in waist-hip ratio with weight loss and its association with change in cardiovascular risk factors. Am J Clin Nutr. 1992;55(6):1086-92. 